\title{
correspondence
}

\section{Financial discrimination}

SIR,-As is shown by a survey I made recently, reported on by May (February 12, page 446), many journals discriminate in various ways against the more or less impoverished. I publish a journal myself and have grounds for believing that such discrimination is unnecessary. It preserves showiness (at the expense of economies which leave the scientific content intact) and profit. Editors of journals are usually not impoverished, and the present system does have real advantages to those with money.

As with other socially irresponsible powers, a remedy requires joint action. I am therefore pursuing the following actions, and call on others to do likewise:

- To submit no paper to an irresponsible journal except when there is no reasonable alternative.

- To avoid citing papers published after the end of 1976 in irresponsible journals, when alternative citations are available.

- To refrain from refereeing papers for irresponsible journals.

Some journals are more irresponsible than others, and one can be more stringent with the worse ones.

$$
\text { Yours faithfully, }
$$

LEIGH VAN VALEN

Department of Biology,

University of Chicago,

Chicago, Illinois 60637, USA

\section{Sex laws and inheritance}

SIR,-The sexual discrimination laws now in force in the UK should not blind us to the existence of one social inequality which has a sound physiological basis. I mean the nature of inheritance.

In general, any one of our chromosomes (or any part of one) may have come from any one of our grandparents: no fragment of genetic material can be identified with a particular grandparent, with the unique exception of the $\mathrm{Y}$ chromosome in men. A man's $Y$ chromosome is certainly derived from his father and from his paternal grandfather and so on. No other chromosome has this singular property.

Consider in particular a woman's $\mathrm{X}$ chromosomes. They assuredly were derived one from her mother and one from her father. But the maternal one -is it in turn from her maternal grandmother or grandfather? It could be from either. Her paternal $X$ chromosome is certainly derived from her paternal grandmother but its pedigree similarly stops short.

Quite generally, any of our forebears, from our grandparents back, may be completely unrepresented in our chromosomes (although crossingover reduces the probability of any such omission).

Therefore, if a woman and her husband intend only their (genetic) descendants to receive their name, title or family silver, they had better ensure that it goes only to their sons and their sons' male descendants.

Yours faithfully,

J. R. JOHNSTONE

Department of Physiology,

University of Western Australia,

Nedlands, Western Australia

\section{Journal guidelines}

SIR,-As Professor Ziman remarks (January 29, page 264), evidence for or against the anonymity of referees is difficult to present. However, my claim that six years editorial experience confirmed the validity of the initial policy statement in the Journal of Aerosol Science can be enlarged on. There were three reasons for identifying referees:

- The authoritarian age is over. Professor Ziman is in error in identifying this as a populist rejection of constraints imposed by the community. It refers. of course, to constraints imposed by a favoured section of the community.

- The standard of critique will be raised. By eliciting specific criticisms in place of diffuse; by "curbing the vanity and pride of those who claim authoritv': by disclosing a possibly partisan opinion in a debated field: by revealing a possible error in referee selection.

- Encouragement and benefit will result to authors. The young scientist may be put in touch with a well-known figure; an argument between equals becomes definable; a senior worker should know the source of critical comment, especially when it comes from a younger person.

The opposing view of Professor Ziman rests largely upon emotional factors. I do not believe that they are exacerbated by disclosing a personal target-rather the reverse. One would expect a referee to excuse himself if asked to deal with the work of a friend or rival were the editor ineptly to place him in an embarrassing situation. Yours faithfully,

$$
\text { C. N. Davies }
$$

University of Essex,

Colchester, UK

\section{Fruit flies as security officers}

SIR,- - Trained dogs have an established role as aids to Customs Inspectors and Airport Security Guards because of their ability to "smell out" concealed drugs or explosives or other forms of contraband. What seems to have been overlooked is the possibility of using insects for the same purpose.

The simpler insects have genetically fixed responses to specific odours, usually resulting in a conspicuous clustering in the vicinity of the odour source which may be of an extremely low absolute intensity. Kikuchi (Jap. J. Genet., 48(2), 105; 1973 and Nature, 243. 36; 1973) isolated a mutant strain of Drosophila melanogaster that was strongly attracted to eighteen chemicals which were repellent to the parent strain. It seems likely, therefore, that a systematic search for other strains selectively responsive to various narcotic or explosive emanations can uncover specific "olfactory mutants" of a practically useful sort.

While there would be obvious obiections to using such species as cockroaches bees or houseflies. the relatively inconspicuous but not unfamiliar fruit flies would probably be an acceptable alternative to some of the existing security checks.

Yours faithfully

$$
\text { R. H. WRIGHT }
$$

6822 Blenheim Street, Vancouver V6N 1R7, Canada

\section{The JPU in modern science}

SiR,-In view of the current interest in citation-counting and other attempts to quantify scientific achievement, I wish to draw attention to a simple concept which may grow in importance in the future. This is the JPU or "Just Publishable Unit" which may be defined as the smallest amount of information which is normally accepted for publication as a separate item in a scientific iournal. An example is the present communication.

Yours faithfully,

\section{Fraser}

Ministry of Natural Resources,

Maple, Ontario, Canada 